\title{
Gel textural characteristics of hair gel with cocoa shell extract by using mixture D-optimal method.
}

\author{
Arief Huzaimi Md Yusof a, b, Siti Salwa Abd Gani ${ }^{\text {b,c }}$,*, Uswatun Hasanah Zaidan d, \\ Mohd Izuan Effendi Halmi ${ }^{\text {e. }}$ \\ ${ }^{a}$ Malaysia Cocoa Board, Cocoa Innovative and Technology Centre, Lot 12621 Nilai Industrial Area, 71800 \\ Nilai, Negeri Sembilan, Malaysia \\ ${ }^{b}$ Halal Products Research Institute, Universiti Putra Malaysia, Puta Infoport, 43400 Serdang, Selangor, \\ Malaysia. \\ ${ }^{\mathrm{c}}$ Department of Agriculture Technology, Faculty of Agriculture, Universiti Putra Malaysia \\ ${ }^{\mathrm{d}}$ Department of Biochemistry, Faculty of Biotechnology and Biomolecular Sciences, Universiti Putra Malaysia. \\ eDepartment of Land Management, Faculty of Agriculture, Universiti Putra Malaysia
}

Received: June 19, 2021. Revised: November 15, 2021. Accepted: December 15, 2021. Published: January 3, 2022.

\begin{abstract}
This study was used a mixture design to optimize the spreadability and viscosity of topical hair gel incorporates cocoa shell extract. The factor of the hair gel ingredient was thickener $(0.2-0.8 \%)$, styling polymer A (2-5\%), styling polymer B (2-6\%), and solvent $(84.63-91.63 \%)$ were studied on two responses selected spreadability and viscosity. The data collected were fitted to the model with high coefficient determination $(\mathrm{R} 2=\mathbf{0 . 9 9 4}$ for the spreadability and 0.9937 for the viscosity). The model can be predicted by showing the good lack of fit test result not significant with the $p$-value bigger than 0.05. From the ramp function simulation, the optimized formulation was selected and established at thickener $(0.55 \%)$, styling polymer A (3.61\%), styling polymer B (3.72\%), and solvent $(\mathbf{8 8 . 5 5 \% )}$ with the spreadability and viscosity at 353.77 g.s and 39.91 pa.s respectively. The benefit of using mixture design in this experiment, it can help a formulator to understand the complex interaction between factors and can easily modify the formulation through ramp function simulation to obtain the desired result. The predicted validation test shows that both values were comparable. Under this condition showed that the model development could be used to predict future observations within the design range thickener $(0.2-0.8 \%)$, styling polymer A $(2-5 \%)$, styling polymer B (2-6\%), and solvent (84.63-91.63\%).
\end{abstract}

Keywords: Cocoa shell, cosmeceutical, hair gel, mixture design

\section{INTRODUCTION}

In the cocoa industry, the cocoa shell is removed in cocoa processing. It is considered a by-product of the cocoa industry that is usually underutilized or considered waste. Although some researches have revealed cocoa shell can be used as fertilizer, and activated carbon [1], investigations of its usage as haircare cosmetic materials have not been vastly carried out. The previous study shows that cocoa shell contains antioxidant compounds by using extraction (water bath) with $80 \%$ of ethanol, $35^{\circ} \mathrm{C}$, for 30 minutes at $120 \mathrm{rpm}$ [2]. The result shows cocoa shells contain antioxidant properties. The previous study done related to the antioxidant and hair subject shows that treatments with antioxidants improved the mechanical properties of irradiated hair and reduced the lipidic peroxidation and protein degradation of hair in the antioxidant-treated samples [3]. SEM images showed that the application of antioxidants to hair fibers leads to an improvement in the cuticle scale along with the hair fiber. This shows the benefit of antioxidants from plant extract to the hair subjected to UV irradiation

In the cosmetic industry, the formulation was one of the important parts to create a good product. The difficulty of the formulator was to explain and understand the complex interaction between an ingredient in the formulation. Furthermore, formulators also face the difficulty to decide what combination of the component can be modified since it is difficult to predict the variation of response such as, spreadability, viscosity, transparency, color, texture characteristic, and so on [4]. However, these parameters are important to evaluate the acceptance or rejection of the product by the consumer. In a previous study done on the formulation of antioxidant juice by using different types of vegetable juice powder (broccoli mixed powder, cabbage mixed powder, carrot-mixed powder). shows high linear and quadratic relations revealed and show the importance to understand the complex interaction between ingredients at the microstructure level [5]. Another study on natural 
lipstick formulation based on pitaya (Hylocereus polyrhizus) seed oil was evaluated its melting point by using a mixture design. The data shows that there is a high correlation between the 4 types of ingredients as a factor to the response melting point. The tools were easily showing that the mixture design can reveal the complex interaction, and how to modify the formulation to obtain the best outcome by reducing time and cost consumption in the experimental design [6]. Furthermore, by using the data, the formulator can decide to modify the ratio of ingredients according to the practical needs to achieve the best formulation within the design range.

In this study, we conducted a spreadability and viscosity study of the hair gel formulation addressing the interaction of the ingredient to the response by using the mixture D-optimal method.

\section{MATERIAL AND METHODS}

The dry cocoa bean used in this study was collected from Pusat Penyelidikan dan Pembangunan Koko, Jengka, Pahang, Malaysia. The chemical ingredient used in this study was the analytical grade. The method used in this study mixture D-optimal method and the analysis was done by using Design Expert 10.

\section{A. Material and chemicals.}

The dry beans were washed to remove any dirt and stored in a $-40{ }^{\circ} \mathrm{C}$ freezer for 24 hours. The cocoa bean was then, freeze-dried for three days and manually removed from the dry shell of the bean. The shell was then ground to $1 \mathrm{~mm}$ by using an IKA grinder and label as Malaysian Cocoa Shell (MCS). Other chemicals used in this study are distilled water, ethanol, thickener, moisturizer, functional polymer A, functional polymer $\mathrm{B}$, humectant, $\mathrm{pH}$ adjusting agent, fragrance, and preservative. All chemicals were in analytical grade and cosmetic grade. The brand and trade name ingredient of the formulation will not be published due to the conflict of interest.

\section{B. Ultrasound-assisted extraction}

The extract of MCS was prepared by mixing $1 \mathrm{~g}$ of powdered MCS and $50 \mathrm{~mL}$ ethanol $(67 \%$ concentration) in a conical flask with a screw cap. Next, the conical flask was placed inside the sonication bath machine (Wise clean $40 \mathrm{kHz}, 296 \mathrm{~W}$, and Korea) at $60{ }^{\circ} \mathrm{C}$ for 26 minutes. The condition of extraction was determined by using response surface methodology (RSM) where the extract condition was optimized and stabilized when mixing with other ingredients to formulate a hair gel. The
RSM technique was performed according to the method described by Azahar et al. (2017) and Pingret (2012) with minor modification [7,8]. The microbubbles generated from the different amplitude of ultrasonic waves cause several physical effects from the cavitation microbubbles through cell walls including shock waves and microjets, improving the heat transfer through the cell walls and increasing pores on the cell surfaces. As a result, better release of target bioactive substances from natural sources [9]. The aqueous extract was filtered using Watman filter paper number 4 , and the solvent was removed using a rotary evaporator (IKA, German). Next, the extract was freeze-dried (Labconco, USA) to get the crude extract (powdered) and labeled as Malaysian Cocoa Shell Extract (MSCE). The powdered extract was stored at $-40{ }^{\circ} \mathrm{C}$ in storage vials.

\section{Formulation of topical hair gel using mixture design}

The experimental design was built by using DesignExpert software. The range value of each ingredient for the experimental run was shown in table 1 . The 4 main ingredients Polyacrylic acid, Polyvinylpyrrolidone, Poly (1-vinylpyrrolidone-coVinyl Acetate), and water was labeled as thickener, functional polymer A, functional polymer B, and solvent respectively. The ingredient was mixed according to the mixture experimental design as shown in table 2 . Then the mixture was neutralized by using a Triethanolamine as a $\mathrm{Ph}$ adjusting agent and mixture with other ingredients such as glycerine, propanediol, benzophenone 4, methylparaben, fragrance oil, and MSCE labeled as a moisturizer, humectant, UV protector, preservatives, fragrance, and active ingredient respectively to make it $100 \mathrm{~g}$ hair gel. The gel was then labeled as topical hair gel (THG). The technique to mix the ingredient, brand, and trade name of each ingredient was not published due to the conflict of interest.

\section{Determined the Spreadability value of $T H G$}

The spreadability value was evaluated by using the texture analyzer instrument with a probe TTC spreadability rig ( $\mathrm{HDP} / \mathrm{SR}) 90^{\circ}$ male cone with matches female cone [10]. $5 \mathrm{~g}$ of THG was filled in the female cone and removed air pockets by using a spatula. Next, the high of the male cone were adjusted from the software and reset as zero. The parameter was chosen from the software at test speed $3 \mathrm{mms}^{-1}$ for a distance of $23 \mathrm{~mm}$. The male cone was moving down to the female cone until it pressed the sample inside and the value was recorded and calculated by the software.

Table 1: Independent variables and their range set. 


\begin{tabular}{ccc}
\hline Independent & \multicolumn{2}{c}{ level } \\
\cline { 2 - 3 } variables $(\%)$ & minimum & maximum \\
\hline Thickener, $\left(\mathrm{X}_{1}\right)$ & 0.2 & 0.8 \\
Functioning & 2 & 5 \\
Polymer $\mathrm{A},\left(\mathrm{X}_{2}\right)$ & &
\end{tabular}

\begin{tabular}{ccc}
$\begin{array}{c}\text { Functioning } \\
\text { Polymer } \mathrm{B}\left(\mathrm{X}_{3}\right)\end{array}$ & 2 & 6 \\
Solvent $\left(\mathrm{X}_{4}\right)$ & 84.63 & 91.63 \\
\hline
\end{tabular}

Table 2: Mixture design of six-ingredient to formulate THG and their observed responses.

\begin{tabular}{|c|c|c|c|c|c|c|c|c|}
\hline Run & $\begin{array}{c}\text { Thickener } \\
(\%)\end{array}$ & $\begin{array}{c}\text { Functioning } \\
\text { Polymer A } \\
(\%)\end{array}$ & $\begin{array}{c}\text { Functioning } \\
\text { Polymer B } \\
(\%)\end{array}$ & $\begin{array}{c}\text { Solvent } \\
(\%)\end{array}$ & $\begin{array}{l}\text { Spreadability } \\
\text { (g.sec) Actual }\end{array}$ & $\begin{array}{l}\text { Spreadability } \\
\text { (g.sec) Predicted }\end{array}$ & $\begin{array}{c}\text { Viscosity } \\
\text { (Pa.s) } \\
\text { Actual } \\
\end{array}$ & $\begin{array}{c}\text { Viscosity } \\
\text { (Pa.s) } \\
\text { Predicted }\end{array}$ \\
\hline 1 & 0.62 & 2.00 & 6.00 & 87.81 & 271.33 & 278.28 & 32.2 & 36.47 \\
\hline 2 & 0.80 & 5.00 & 2.00 & 88.63 & 905.61 & 831.66 & 1156.32 & 1130.70 \\
\hline 3 & 0.80 & 2.51 & 3.70 & 89.42 & 586.19 & 536.12 & 155.4 & 154.46 \\
\hline 4 & 0.49 & 3.26 & 2.00 & 90.68 & 377.22 & 349.65 & 93.48 & 91.91 \\
\hline 5 & 0.20 & 2.00 & 3.32 & 90.91 & 19.80 & 16.43 & 0.631 & 0.74 \\
\hline 6 & 0.20 & 5.00 & 2.00 & 89.23 & 56.70 & 48.50 & 7.098 & 4.90 \\
\hline 7 & 0.62 & 2.00 & 6.00 & 87.81 & 284.07 & 278.28 & 40.63 & 36.47 \\
\hline 8 & 0.20 & 5.00 & 2.00 & 89.23 & 29.91 & 48.50 & 2.535 & 4.90 \\
\hline 9 & 0.40 & 3.90 & 3.10 & 89.03 & 204.48 & 230.07 & 41.09 & 43.55 \\
\hline 10 & 0.20 & 5.00 & 3.33 & 87.90 & 44.65 & 30.56 & 2.962 & 2.49 \\
\hline 11 & 0.80 & 5.00 & 6.00 & 84.63 & 557.21 & 542.42 & 169.2 & 143.53 \\
\hline 12 & 0.80 & 5.00 & 2.00 & 88.63 & 762.19 & 831.66 & 1105 & 1130.70 \\
\hline 13 & 0.80 & 3.26 & 4.33 & 88.04 & 508.07 & 542.44 & 125.4 & 125.93 \\
\hline 14 & 0.20 & 3.24 & 5.51 & 87.48 & 14.83 & 23.29 & 1.995 & -0.038 \\
\hline 15 & 0.80 & 2.00 & 2.00 & 91.63 & 583.46 & 611.88 & 201.2 & 177.98 \\
\hline 16 & 0.80 & 5.00 & 6.00 & 84.63 & 530.54 & 542.42 & 117.9 & 143.53 \\
\hline 17 & 0.45 & 5.00 & 4.33 & 86.65 & 278.87 & 283.06 & 95.87 & 95.17 \\
\hline 18 & 0.80 & 2.00 & 2.00 & 91.63 & 614.75 & 611.88 & 154.2 & 177.98 \\
\hline 19 & 0.20 & 3.91 & 6.00 & 86.32 & 33.19 & 21.89 & 1.762 & 3.08 \\
\hline 20 & 0.20 & 2.00 & 5.10 & 89.13 & 26.86 & 30.91 & 0.9364 & 1.37 \\
\hline
\end{tabular}

Table 3: Condition for the ramp function graph.

\begin{tabular}{cccccccc}
\hline Solution & $\begin{array}{c}\text { Thickener } \\
(\%)\end{array}$ & $\begin{array}{c}\text { Functional } \\
\text { polymer A } \\
(\%)\end{array}$ & $\begin{array}{c}\text { Functional } \\
\text { polymer B } \\
(\%)\end{array}$ & $\begin{array}{c}\text { Solvent } \\
(\%)\end{array}$ & $\begin{array}{c}\text { Spreadability } \\
\text { (g.sec) }\end{array}$ & $\begin{array}{c}\text { Viscosity } \\
\text { (Pa.s) }\end{array}$ & Desirability \\
\hline 1 & 0.55 & 3.61 & 3.72 & 88.55 & 352.68 & 40.02 & 1 \\
2 & 0.53 & 3.91 & 3.99 & 88.00 & 342.84 & 39.87 & 1 \\
3 & 0.45 & 3.52 & 3.02 & 89.44 & 274.95 & 38.33 & 1 \\
\hline
\end{tabular}

E. Determined the Viscosity of THG.

The viscosity of the samples was determined by using Rheometer AR2000ex (TA Instruments, U.S.A.) [11]. A cone plate with a diameter of $40 \mathrm{~mm}$ and 1.0.7 degrees was used to measure the sample. About $0.5 \mathrm{~g}$ of the sample was placed at the plate and removed its excess amount by using a spatula. Samples were measured its shear stress and the shear rate at 22 points in 30 minutes at room temperature. The rheology data was fitted to the HerschelBulkley model.

F. Optimizing, ramp function, and t-test.
The condition for the THG was optimized from the model by using the ramp function where the goal of factors, response, desirability value, and the limits of response can be set through the software. The equation (equation 1 and equation 2) built by the software was used to determine the best condition based on the desired response value. The preferable range value of spreadability and viscosity that were set in the ramp function was determined from the several data obtained from commercial hair gel brands in the market. The desirability was fit to a value of 1 show that a high probability to obtain a good result similar to the model. The lowest desirability value shows the negative result was obtained through the experiment due to the noise $[12,13]$ Three solutions were selected, where the 
best formulation was labeled as solution 1, while the other solution was used to validate the model. The model was then validated by performing a T-test on Minitab software (version14, Minitab, USA) as shown in table 3. All the experimental simulations were run in triplicate.

$$
\begin{gathered}
Y_{\text {Spreadability }}=2786.07269 x_{1}+215.57954 x_{2}+226.94526 x_{3}-1.97674 x_{4}+82.07358 x_{1} x_{2}-128.45183 x_{1} x_{3} \\
-18.68897 x_{1} x_{4}-9.57424 x_{2} x_{3}-2.42477 x_{2} x_{4}-2.15024 x_{3} x_{4} \\
Y_{\text {Viscosity }}=60800.51712 x_{1}-4358.70419 x_{2}-1481.53288 x_{3}-4.10085 x_{4}+13833.13865 x_{1} x_{2}+459.64021 x_{1} x_{3} \\
-459.64021 x_{1} x_{4}+377.34952 x_{2} x_{3}+47.80560 x_{2} x_{4}+16.54702 x_{3} x_{4}-303.93633 x_{1} x_{2} x_{3} \\
-154.18469 x_{1} x_{2} x_{4}-9.28055 x_{1} x_{3} x_{4}-3.49872 x_{2} x_{3} x_{4}
\end{gathered}
$$

Where $x_{1}, x_{2}, x_{3}$ and $x_{4}$ were thickener, functioning polymer $\mathrm{A}$, functioning polymer $\mathrm{B}$, and solvent respectively.

Table 4: Analysis of variance for a fitted quadratic model of ingredient ratio THG.

\begin{tabular}{cccccccc}
\hline \multirow{2}{*}{ Source } & \multicolumn{3}{c}{ Spreadability Value } & \multicolumn{3}{c}{ Viscosity } \\
\cline { 2 - 7 } & Mean Square & F-Value & p-value & Mean Square & F-Value & p-value \\
\hline Model & $1.647 \mathrm{E}+005$ & 94.07 & $<0.0001$ & $1.622 \mathrm{E}+005$ & 256.14 & $<0.0001^{\mathrm{a}}$ significant $^{\mathrm{a}}$ \\
Linear Mixture & $4.706 \mathrm{E}+005$ & 268.76 & $<0.0001$ & $3.577 \mathrm{E}+005$ & 564.75 & $<0.0001^{\mathrm{a}}$ \\
$\mathrm{X}_{1} \mathrm{X}_{2}$ & 137.88 & 0.079 & 0.7847 & 137.74 & 0.22 & 0.6574 \\
$\mathrm{X}_{1} \mathrm{X}_{3}$ & 353.46 & 0.20 & 0.6628 & 13392.65 & 21.15 & $0.0037^{\mathrm{a}}$ \\
$\mathrm{X}_{1} \mathrm{X}_{4}$ & 7.22 & $4.125 \mathrm{E}-$ & 0.9501 & 12898.91 & 20.37 & $0.0040^{\mathrm{a}}$ \\
\hline $\mathrm{X}_{2} \mathrm{X}_{3}$ & 1200.82 & 0.69 & 0.4269 & 208.03 & 0.33 & 0.5874 \\
$\mathrm{X}_{2} \mathrm{X}_{4}$ & 79.42 & 0.045 & 0.8356 & 179.29 & 0.28 & 0.6138 \\
$\mathrm{X}_{3} \mathrm{X}_{4}$ & 223.41 & 0.13 & 0.7284 & 133.59 & 0.21 & 0.6622 \\
$\mathrm{X}_{1} \mathrm{X}_{2} \mathrm{X}_{3}$ & - & - & - & 54.68 & 0.086 & $0.0015^{\mathrm{a}}$ \\
$\mathrm{X}_{1} \mathrm{X}_{2} \mathrm{X}_{4}$ & - & - & - & 180.48 & 0.28 & $0.0477^{\mathrm{a}}$ \\
$\mathrm{X}_{1} \mathrm{X}_{3} \mathrm{X}_{4}$ & - & - & - & $3.577 \mathrm{E}+005$ & 564.75 & 0.7788 \\
$\mathrm{X}_{2} \mathrm{X}_{3} \mathrm{X}_{4}$ & - & - & - & 137.74 & 0.22 & 0.6126 \\
Residual & 1751.17 & - & - & 633.31 & - & - \\
Lack of Fit & 1188.32 & 0.51 & 0.7590 & 16.6814 & 0.0220 & 0.8878 \\
$\mathrm{R}^{2}$ & 0.9883 & & & 0.9982 & & Not \\
Predicted $\mathrm{R}^{2}$ & 0.9543 & & & 0.9943 & & significant \\
\hline a & & & & &
\end{tabular}

a denotes a significant difference at $\mathrm{p}<0.05$.

*The Model F-value of 256.14 implies the model is significant. There is only a $0.01 \%$ chance that an F-value this large could occur due to noise. Values of "Prob $>$ F" less than 0.0500 indicate model terms are significant. Values greater than 0.1000 indicate the model terms are not significant.

Table 5: T-test spreadability table of verification of the model.

\begin{tabular}{ccccccc}
\hline Solution & $\begin{array}{c}\text { Number of } \\
\text { samples }\end{array}$ & Mean & $\begin{array}{c}\text { Standard } \\
\text { deviation }\end{array}$ & $\begin{array}{c}\text { Standard error } \\
\text { mean }\end{array}$ & T-value & P-value \\
\hline 1 & 3 & 353.77 & 2.26 & 1.305 & 0.83 & 0.493 \\
2 & 3 & 336.36 & 4.49 & 2.592 & -2.5 & 0.13 \\
3 & 3 & 269.07 & 8.37 & 4.832 & -1.22 & 0.34 \\
\hline
\end{tabular}

Table 6: T-test viscosity table of verification of the model

\begin{tabular}{ccccccc}
\hline Solution & $\begin{array}{c}\text { Number of } \\
\text { samples }\end{array}$ & Mean & $\begin{array}{c}\text { Standard } \\
\text { deviation }\end{array}$ & $\begin{array}{c}\text { Standard error } \\
\text { mean }\end{array}$ & T-value & P-value \\
\hline 1 & 3 & 39.91 & 0.4 & 0.2309 & -0.91 & 0.459 \\
2 & 3 & 37.79 & 0.98 & 0.5658 & -3.68 & 0.067 \\
3 & 3 & 40.64 & 0.57 & 0.3291 & 7.02 & 0.02 \\
\hline
\end{tabular}




\section{Statistical analysis.}

The statistical analysis was done at fit summary selection (from the software) where the software compared the data to any polynomial order such as Linear, quadratic, special cubic, or cubic. The best order was suggested by the software and subjected to an analysis of variance (ANOVA). The successful data fitted to the model subjected to build the simulation equation and model graph (contour and surface graph) to be diagnosed and optimized [14]. All statistical analysis on the data and model was done by using Expert Design software and the T-test validation was performed on Minitab Software.

\section{RESULT AND DISCUSSION}

\section{A. Model fitting for THG.}

The data were fitted to the model and predicted by using equations 1 and 2 built by the software. The equation was generated by the software according to the data obtained from the experiment. The equation was then used in the simulation based on mathematical perception to optimize the response according to the needs of the outcome. The polynomial equation was used to build the regression of the model as described by Marcos Almeida Bezerra et al, (2008) [15] and the technique of mixture design was described by Safaei et al. (2019) [16] and Wang and Fang (2010) [17]. This can be shown in table 4 where the lack of fit test

show not significant $(\mathrm{p}>0.05)$. The actual data and predicted data were presented in table 2. The ANOVA analysis shows the spreadability data were fit to the quadratic model and viscosity data were fit to the special cubic model. The different fitted model on the response shows that complex interaction between the ingredient can be evaluated. For example, there is no significant interaction between thickener and functional polymer $\mathrm{B}$ to evaluate the spreadability of the sample. While on the other hand, to evaluate viscosity, the interaction thickener and functional polymer B were influenced by the solvent (within the design range). The complex interaction between ingredients (significant or not significant) was presented in table 4.

\section{B. Optimizing the ingredient THG ratio.}

The higher spreadability is a greater interest in cosmetics. It is determined by the ratio between area and weight and the semisolid formulation was spread on the targeted surface evenly [18]. Figure 1 shows the spreading value of THG by presenting the relation between thickener, functional polymer A and functional polymer $\mathrm{B}$. It shows that the characteristic of polymer A and B was not similar to each other when mixed with the thickener ingredient. Polymer A was not given any influence on the spreadability as the percentage of functional polymer A increased but functional polymer B increased the value of spreadability as the percentage of ingredients increased. As for thickener, the spreadability value was decreased when the percentage of thickener increased. It is due to the hardening agent released from the thickener ingredient that causes repulsion between chains, increasing the crosslinking between chains decreased its viscosity. The good value of spreadability plays an important role in sensory evaluation and acceptance of the consumer [19]. The value spreadability obtain from the MD was between 19.80 to $905.61 \mathrm{~g}$.sec, with the coefficient determination $\mathrm{R}^{2}=0.9883$. The predicted coefficient determination was 0.9543 was not too far from the $\mathrm{R}^{2}$ showed that the model could predict the future observation within the design ranged

The viscosity of the topical formulation product played an important role in determining the function of cosmetic hair products [20]. It is also welldisplayed data in packaging process engineering as the product viscosity will be determined by the type of packaging suitable for the product. The viscosity for this study was displayed between 0.631 to 1156.32 pa.s. The data were fit to the model with $\mathrm{p}<0.0001$ and lack of fit test show not significant $(p>0.05)$ show that the model can be used to predict the future observation within the design

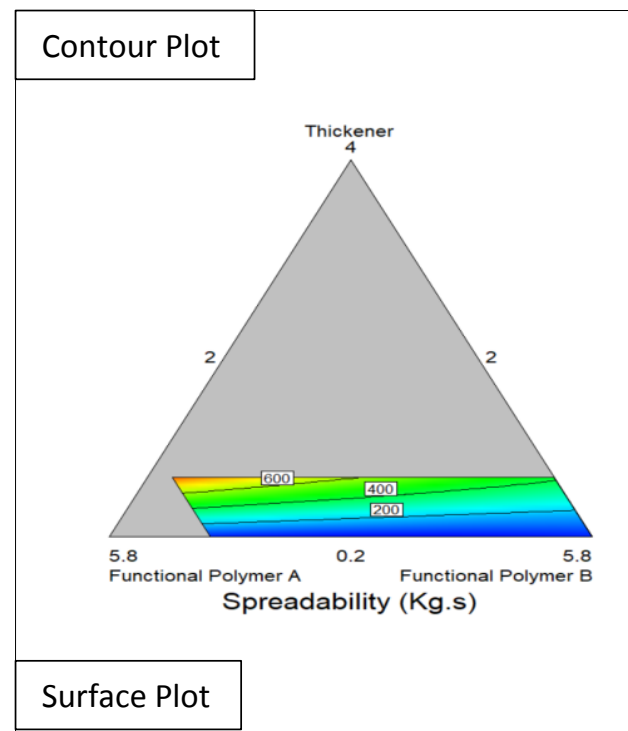




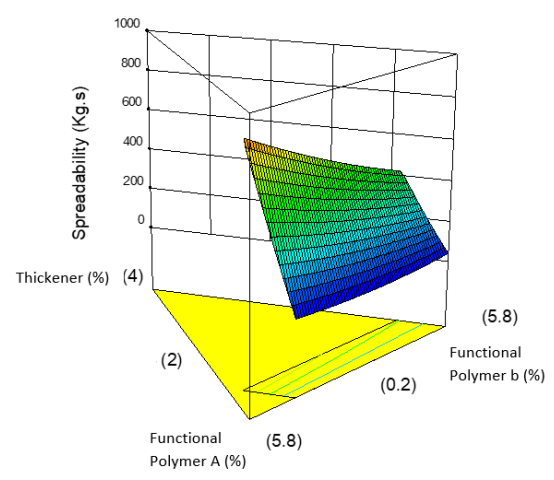

Figure 1: Contour plot and surface plot of thickener, functional polymer A, and functional polymer B concentration

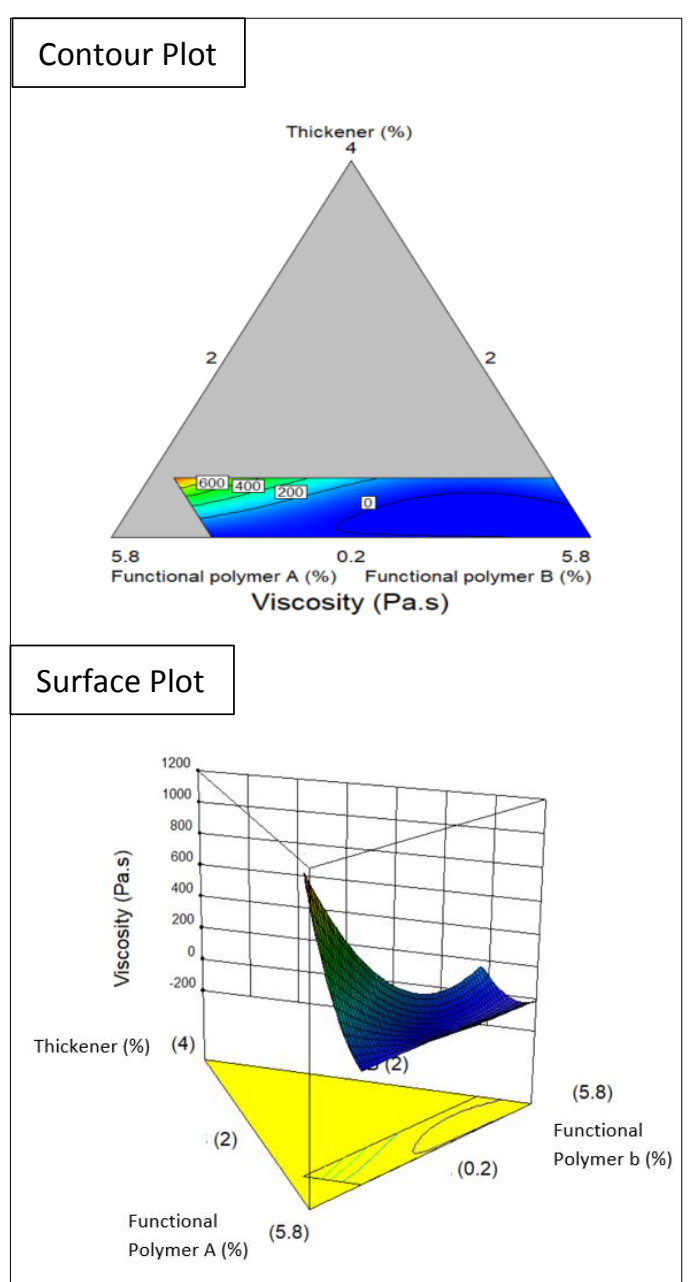

Figure 2: Contour plot and surface plot of thickener, moisturizer, and styling polymer concentration.

range. From figure 2, the data displayed a strong relationship between. thickener and functional polymer B compared to functional polymer A. The viscosity was decreased as the thickener increased and functional polymer $\mathrm{B}$ increased. On the other hand, the viscosity was almost similar as the concentration of functional polymer A increased. But this behavior was a change at thickener with a concentration between 2.8 and 5.8 percent. The determination of viscosity is important to evaluate the stability study later on [21]. The viscosity of THG was decreased and increased back as the concentration of functional polymer A was increased. This is due to the complex interaction between factors. The viscosity of a formulation will depend on its physicochemical characteristics, and on the temperature conditions to which it is subjected [22].

\section{Verification of the model.}

This study was conducted to verify the accuracy of the model. The verification was conducted by simulating with a different set of ingredients (various concentrations) within the design range. The desirability function for this simulation was fit at 1.00 (highest desirability) and the factor was set to lower thickener, moderate polymer A and B, and low solvent. The T-test shows that the data is not significant $(p>0.05)$ between the predicted data and actual data. The result was displayed in tables 5 and 6 and the graph (solution 1) was displayed in the figure 3 and 4 . Three same sets for each response were used to determine its model accuracy and to optimize the formulation. Based on the result obtained, both models gave comparable data. Therefore, the model obtained by the d-optimal design was satisfactory. The not significant form $\mathrm{T}$ test showed that the model can be repeated at any point within the design range. The optimized formulation was selected as follow: thickener $(0.55 \%)$, functional polymer A $(3.61 \%)$, functional polymer B (3.72\%), solvent (88.55\%) with spreadability 353.77 g.sec and viscosity 39.91 pa.s.

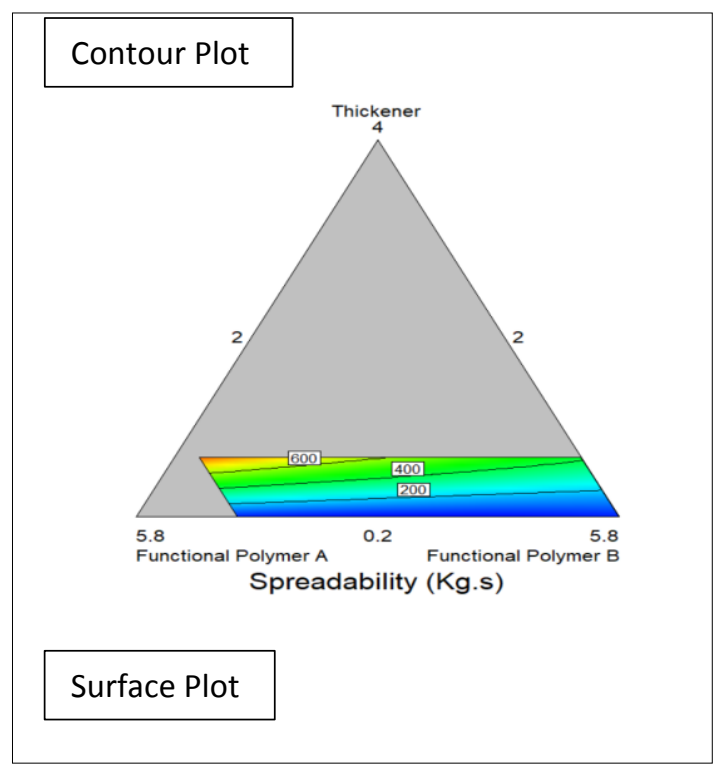




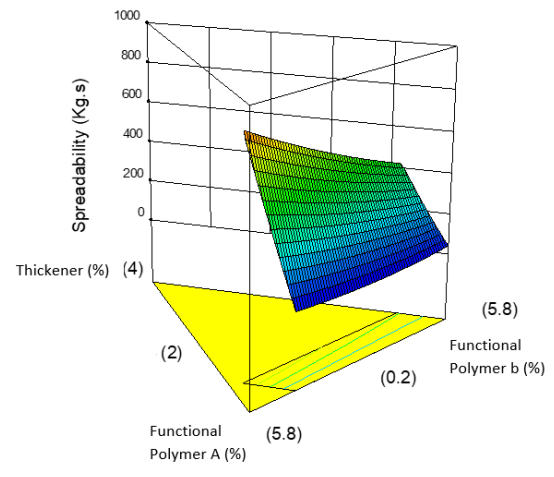

Figure 3: Contour plot and surface plot of thickener, functional polymer A, and functional polymer B concentration for solution 1

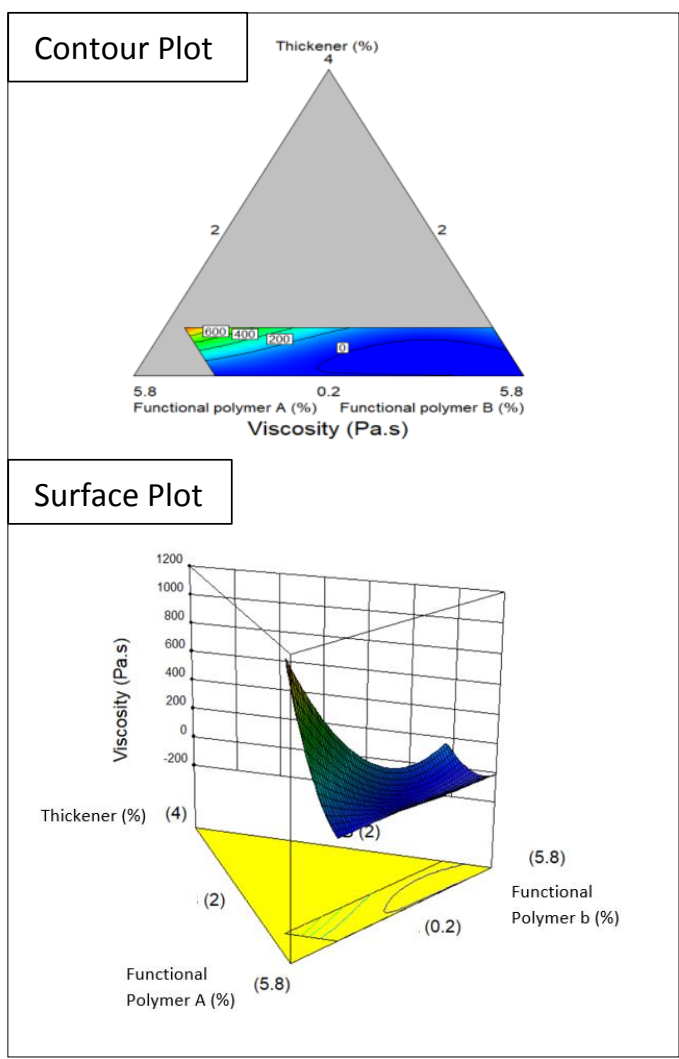

Figure 4: Contour plot and surface plot of thickener, functional polymer $\mathrm{A}$, and functional polymer B concentration for solution 1

\section{CONCLUSION}

The mixture design is one of the useful tools to evaluate the complex interaction between an ingredient in the formulation. The results show that the model can be used to predict future observations within the design range. The statistic of the model shows that the two response (spreadability and viscosity) was significant $(\mathrm{p}<0.05)$. the result shows that the linear interaction was significant while for the viscosity, the interaction was in the cubic model. Therefore, in this study the THG was successfully formulated, the spreadability and viscosity of the formulation were evaluated properly.

\section{ACKNOWLEDGMENTS}

This work was supported by the Malaysia Cocoa Board, the Halal Product Research Institute, and the University Putra Malaysia (UPM).

\section{REFERENCES}

[1] F. Ahmad, W.M.A.W. Daud, M.A. Ahmad, R. Radzi, Using cocoa (Theobroma cacao) shell-based activated carbon to remove 4nitrophenol from aqueous solution: Kinetics and equilibrium studies, Chem. Eng. J. 178 (2011) $461-467$. doi:10.1016/j.cej.2011.10.044.

[2] A.A. Karim, A. Azlan, A. Ismail, P. Hashim, N.A. Abdullah, Antioxidant Properties of Cocoa Pods and Shells, Malaysian Cocoa J. 8 (2014).

[3] E. Fernández, B. Martínez-Teipel, R. Armengol, C. Barba, L. Coderch, Efficacy of antioxidants in human hair, J. Photochem. Photobiol. B Biol. 117 (2012) 146-156. doi:10.1016/j.jphotobiol.2012.09.009.

[4] P. Herh, J. Tkachuk, S. Wu, M. Bernzen, B. Rudolph, Rheology of pharmaceutical and cosmetic semisolids, Am. Lab. 30 (1998) 12-14.

[5] M.B. Kim, J.Y. Ko, S. Bin Lim, Formulation Optimization of AntioxidantRich Juice Powders Based on Experimental Mixture Design, J. Food Process. Preserv. 41 (2017). doi:10.1111/jfpp.12897.

[6] N. Kamairudin, S.S. Abd Gani, H.R. Fard Masoumi, P. Hashim, Optimization of natural lipstick formulation based on pitaya (hylocereus polyrhizus) seed oil using doptimal mixture experimental design, Molecules. 19 (2014) 16672-16683. doi:10.3390/molecules191016672.

[7] N.F. Azahar, S. Salwa, A. Gani, N. Fadzillah, M. Mokhtar, Optimization of phenolics and flavonoids extraction conditions of Curcuma Zedoaria leaves using response surface methodology, Chem. Cent. J. (2017) 1-10. doi:10.1186/s13065017-0324-y.

[8] D. Pingret, A.S. Fabiano-Tixier, C. Le Bourvellec, C.M.G.C. Renard, F. Chemat, 
Lab and pilot-scale ultrasound-assisted water extraction of polyphenols from apple pomace, J. Food Eng. 111 (2012) 73-81. doi:10.1016/j.jfoodeng.2012.01.026.

[9] T. Leong, M. Ashokkumar, S. Kentish, THE FUNDAMENTALS OF POWER ULTRASOUND - A REVIEW, Med. Phys. 38 (2011) 3392. doi:10.1118/1.3611561.

[10] P. Glibowski, P. Zarzycki, M. Krzepkowska, The rheological and instrumental textural properties of selected table fats, Int. J. Food Prop. 11 (2008) 678686. doi:10.1080/10942910701622599.

[11] M.T. Islam, N. Rodríguez-Hornedo, S. Ciotti, C. Ackermann, Rheological characterization of topical carbomer gels neutralized to different $\mathrm{pH}$, Pharm. Res. 21 (2004) 1192-1199. doi:10.1023/B:PHAM.0000033006.11619. 07.

[12] R.L. Lorza, C.B. Labari, P.J.R. Fuente, Using the Multi-Response Method with Desirability Functions to Optimize the Zinc Electroplating of Steel Screws, Metal. 8 (2018) 711. doi:10.3390/met8090711.

[13] R. Gohil, A. Patel, T. Pandya, A. Dharamsi, Optimization of Brinzolamide loaded Microemulsion using Formulation by Design approach: Characterization and Invitro evaluation, Curr. Drug Ther. 14 (2019) $1-18$.

doi:10.2174/157488551466619010411580 2.

[14] E. Ghafari, M. Bandarabadi, H. Costa, E. Júlio, Prediction of fresh and hardened state properties of UHPC: Comparative study of statistical mixture design and an artificial neural network model, J. Mater. Civ. Eng. 27 (2015) 1-11. doi:10.1061/(ASCE)MT.19435533.0001270 .

[15] M.A. Bezerra, R.E. Santelli, E.P. Oliveira, L.S. Villar, L.A. Escaleira, Response surface methodology (RSM) as a tool for optimization in analytical chemistry, Talanta. $\quad 76 \quad$ (2008) 965-977. doi:10.1016/j.talanta.2008.05.019.

[16] F. Safaei, K. Abhari, N.K. Khosroshahi, H. Hosseini, M. Jafari, Optimisation of functional sausage formulation with konjac and inulin: Using D-Optimal mixture design, Foods Raw Mater. 7 (2019) 177184. doi:10.21603/2308-4057-2019-1-177184.

[17] P. Sen Wang, J.J. Fang, The optimization of medicine formulation using mixture experiments, Proc. Int. MultiConference Eng. Comput. Sci. 2010, IMECS 2010. III (2010) 1801-1806.

[18] T.A.R.E. Both, Texture analysis of cosmetic thickeners for aqueous surfactant systems, (2019) 52-54.

[19] S. Ozkan, T.W. Gillece, L. Senak, D.J. Moore, Characterization of yield stress and slip behaviour of skin/hair care gels using steady flow and LAOS measurements and their correlation with sensorial attributes, Int. J. Cosmet. Sci. 34 (2012) 193-201. doi:10.1111/j.1468-2494.2012.00702.x.

[20] M. Estanqueiro, M.H. Amaral, J.M. Sousa Lobo, Comparison between sensory and instrumental characterization of topical formulations: impact of thickening agents, Int. J. Cosmet. Sci. 38 (2016) 389-398. doi:10.1111/ics.12302.

[21] P. Stephane, Stability of Cosmetic Formulations Containing UV Filters and Preservatives, Based on Physical and Chemical Parameters, MOJ Toxicol. 1 (2015)

12-21. doi:10.15406/mojt.2015.01.00003.

[22] V.C.K.N. Deuschle, R.A. Norbert Deuschle, M.R. Bortoluzzi, M.L. Athayde, Physical chemistry evaluation of stability, spreadability, in vitro antioxidant, and photo-protective capacities of topical formulations containing calendula officinalis L. Leaf extract, Brazilian J. Pharm. Sci. $51 \quad$ (2015) 63-75. doi:10.1590/S1984-82502015000100007.

\section{Creative Commons Attribution License 4.0 (Attribution 4.0 International, CC BY 4.0)}

This article is published under the terms of the Creative Commons Attribution License 4.0

https://creativecommons.org/licenses/by/4.0/deed.en_US 